\title{
ORIGINAL CONTRIBUTION \\ Entrepreneurial Models of Inclusive Civil Culture: The Case of Zapopan Agro Ecological Park
}

\author{
Jose G. Vargas-Hernandez * \\ University Center for Economic and Managerial Sciences, University of Guadalajara, Guadalajara, Mexico
}

\begin{abstract}
This research aims to analyze the model of entrepreneurial, inclusive civic culture created and developed in the Zapopan Agro ecological Park (PAZ). Based on the need to rescue vacant urban land use with the participation of residents residing in the surrounding colonies, social movements, civil society, and local government, they have designed and implemented actions to create PAZ (PEACE). The Zapopan Agro ecological Park is an area of green innovation where in addition to the cultivation of vegetables, vegetables, medicinal plants, and decoration under relations of cooperation, trust, and community support, the formation of social capital that sustains a culture of peace based on environmental sustainability activities. The results of the implementation of this project, born from the bottom of the social and power structures, constitute a significant experience in the regeneration of public spaces and green areas that provides greater economic efficiency in terms of family income, a greater relevance of equity, inclusion and social justice and improvement of environmental sustainability. It is concluded that Zapopan Agro ecological Park is a model of entrepreneurial, inclusive civil culture. This park marks a milestone in the regeneration of public spaces with a project of social and environmental relevance. The analysis and study of this case, Zapopan Agro ecological Park as an urban green innovation area, has the potential to connect the sphere of bio-economy with the requirements of urban development and land uses.
\end{abstract}

Index Terms - Inclusive Civic Culture, Agro Ecological Park, Environmental Sustainability, Zapopan.

Received: 2 April 2020; Accepted: 19 November 2020; Published: 19 December 2020

\section{Introduction}

The Zapopan Agro ecological Park is located in "Closed Saint Laura" within Saint Margaret colony in the municipality of Zapopan, State of Jalisco. The located zones will be defined within the municipality of Zapopan. The population of Zapopan in 2015, according to Inter Census Survey, was 1,332,272 people; 48.8 percent of men and 51.2 percent of women.

Table I

Population of municipality of Zapopan in 2015

\begin{tabular}{llll}
\hline Total & Percentage in the municipality & Men & Women \\
\hline $1,332,272$ & 100.00 & 649,671 & 682,601 \\
\hline
\end{tabular}

Comparing the estimated population in 2015 with the population in 2010 , it can be perceived that the population increased 7.1 percent in five years. It is estimated that in 2020 this population will increase close to 1,414,972 inhabitants. Nowadays, 689,327 million are men and 725,645 are women, representing 16.92 percent of the total population of Jalisco. In 2010 the municipality counted in total of 234 localities. The municipal head of Zapopan is the most populated locality with 1,142,483 people, representing $91.9 \%$ of the population, followed by Saint Francis Tesistan with $5.0 \%$, Sale of the Shipyards with $0.5 \%$, The Doves Country Development with $0.4 \%$ percent and Nextipac with $0.3 \%$ percent of the municipal total. (IIEG, 2016).

Most of the existing buildings have electricity, but only a few have access to piped water and drainage. The constructions are made with timber, concrete, bricks, and adobe. The municipality offers public lighting services, markets, trails, parking lots, cemeteries, roads, public toilets, public security, traffic, parks, gardens, and sports centers. Regarding basic services, $94.8 \%$ of the installed infrastructure has potable water, $96.9 \%$ of sewage, and $98.9 \%$ of electric energy.

Most of the municipality of Zapopan (85.4\%) has a semi-warm climate, half damp. The average annual temperature is $20.5 \mathrm{C}$, while the maximum and minimum average oscillates between $32.1 \mathrm{C}$ and $8.4 \mathrm{C}$, respectively. The climate of the municipality is temperate, semi-dry, with dry winters and dry springs. It is semi-warm with benign winter. It also has an average annual temperature of $23.5 \mathrm{C}$ and an average annual rainfall of 906.1 millimeters with rainfalls from June to October.

The lands of the municipality are mostly composed of rocks, basalt, and tuff. The dominant soils have Eugic Regosol, Haplic Feozem, and chromic Luvisol. The predominant soil is the Phaeozem (Feozem), with almost $50.6 \%$, and it is presented in any type of land relief. It has a dark, soft, rich surface layer with organic matter and a lot of nutrients. Most of the land is only used for agricultural purposes.

\footnotetext{
*Email: josevargas@cucea.udg.mx
} 
The municipality also has three characteristic forms of relief. In a higher percentage, the injured zones are formed by a height of 1,500 to 2,000 meters, following the flat and semi-flat areas. The main elevations of the municipality are The Cabbage Hills (2,200 masl), The Tepopote (1950 masl), The Donky Table (1,700 masl), The Tule (2,050 masl), The Chapulin $(2,000$ masl $)$ high $(1,990$ masl $)$, The Colli $(1,950$ masl), The Flat $(1,800$ masl), The Masahuate (2,100 masl), and the Cave $\mathrm{W}$ with (1,900 masl).

The municipality of Zapopan registered the highest education levels in 2012 with 10.4 years as the average. Zapopan also has the lowest education gap (28.6\%) and follows Guadalajara in a concentration of enrollment with $27.0 \%$.

\section{Natural Resources and Economics}

The natural wealth of the municipality is represented by 11,400 hectares of forest, where pine, oak, creton, jonote, madromo, oak, oyamel and tepame predominate. Its mineral resources are deposits of marble, kaolin, feldspar, agate, tezontle, gravel, and sand (clay). The vegetation of the municipality is conformed mostly by pine and oak; both species are in the forests of the municipality: The Spring Forest, The Nixticuil Forest, and The Sentinel Forest.

The current fauna of the place includes 106 species of animals such as white-tailed deer, puma, lynx, coyote, gray fox, badger, hare, and raccoon, among others. Nearly 137 species of migratory and resident birds have been identified and can be observed hawks, eagles, herons, thrushes, quail, roadrunners, woodpeckers, etc.

Local crops include vegetables, fruits, and seeds like corn, sorghum, zucchini, tomato, chickpea, avocado, mango, and plum. Poultry, beef cattle, pig, sheep, goat meat, and hives are also raised. A great industrial activity is developed. Companies like Motorola and Coca-Cola, among others. According to DENUE, the municipality of Zapopan by 2015 had 49,543 economic units, and its sectors showed a predominance of economic service units, representing $47.3 \%$ of the total companies within the municipality (IIEG, 2016).

The municipality if Zapopan has important shopping centers, named Homeland Mall, Mall of the Sun, Pretty Mall, University, Mexico Mall (one part), Antares Mall, The Great Mall, SAM'S, Price Club, Wall- Mart, Saint Isidro Mall. Financial, professional, technical, administrative, communal, social, personal, tourist, and maintenance are provided. Regarding supply, in terms of popular consumption services, this need is covered by 2,571 grocery stores selling food and beverages, 485 butchers, and 459 establishments selling prepared foods). In Zapopan there are 15 municipal markets and 77 established markets, which makes this municipality a center of supply of localities and surrounding municipalities. The Market of the Sea stands out for its variety and quality of its products.

The number of insured workers also increased this year, where Social Security Mexican Institute (IMSS) reported a total of 327,641 workers newly registered, representing 55,025 more insured workers compared to the same month in 2012 (IIEG, 2016). Also, by 2015 life expectancy in Jalisco were of 75 years old; 73 for men and 78 for women (IIEG, 2015). The Economically Active Population (EAP) represents $45.20 \%$ of the to- tal population that constitute 562,233 habitants, of whom (96.49\%) are employed, and the rest (3.51\%) are unemployed. 6,293 inhabitants are employed in the primary sector of the economy (Agriculture, Livestock, Forestry, hunting, and fishing), 141,375 inhabitants in the secondary sector (Mining, oil and gas extraction, manufacturing, electricity, water, and construction) 388,48 work in the tertiary sector (Government, transportation, commerce, and other services). And the remaining 6,781 inhabitants do not specify the sector to which their economic activity belongs (Zapopan Government, 2016).

Gross Domestic Product in 2015 was 889,703 pesos at 2008 prices. The per capita gross domestic product was 146,746 pesos (INEGI, 2011). The participation of Zapopan in the Gross Domestic Product in 2000 was 10630.2 (adjusted million dollars), which represented 31.9\%, placing it in the second municipality in Jalisco, only after Guadalajara with $43.6 \%$.

GDP of Guadalajara and Zapopan as a percentage of the GDP of Jalisco 2000-2009 at current prices are shown below.

Table II

GDP of Guadalajara and Zapopan as a percentage of the GDP of Jalisco 2000-2009 at current prices

\begin{tabular}{lll}
\hline Region & 2000 & 2009 \\
\hline Guadalajara & 34.79 & 12.29 \\
Zapopan & 20.50 & 10.22 \\
\hline
\end{tabular}

From the analysis of these data, it can be observed that there was a reduction in Zapopan for the GDP.

Zapopan is also one with the highest index of wealth and income in the GDP of the State of Jalisco. Its urban panorama is made up of modern buildings and luxurious shopping centers, residential housing, and green areas that show the highest level in the metropolitan area of Guadalajara (MAG). For the year 2013, intermediate consumption was 108,762 million pesos (Zapopan Government, 2016).

The municipality has air transportation, with a military base that receives airplanes DC-9 and the airport The Barley, a particular property able to receive airplanes. Near Zapopan is the International Airport of Guadalajara Miguel Hidalgo y Costilla for the public air service which is located 50 minutes from the municipal center. The land transportation to the municipality of Zapopan is done through the Mexico-Nogales, GuadalajaraSaltillo, and Guadalajara-Christmas Bar roads. It has a network of dirty and paved roads that communicate to localities. Because of its importance, the highway that connects with the north of the State of Jalisco with the State of Zacatecas stands out. Rail transportation is carried out through the Guadalajara-Nogales line of the Pacific Railway system, only for cargo movement. Through the municipality passes the train called Touristic Tequila that goes from Guadalajara to the population of Tequila.

The terrestrial foreign transportation is done in direct buses for passengers concentrated in the terminals located in Zapopan and other places such as Tlaquepaque and Tonala in the Metropolitan Area of Guadalajara. Urban and rural transportation is done in rental vehicles, private vehicles, and buses. It also has a bus terminal which is next to the roundabout Emiliano Zapata, on the road to Tesistan. The nearest ports are Vallarta Port and Manzanillo, both located on the Pacific Ocean. 


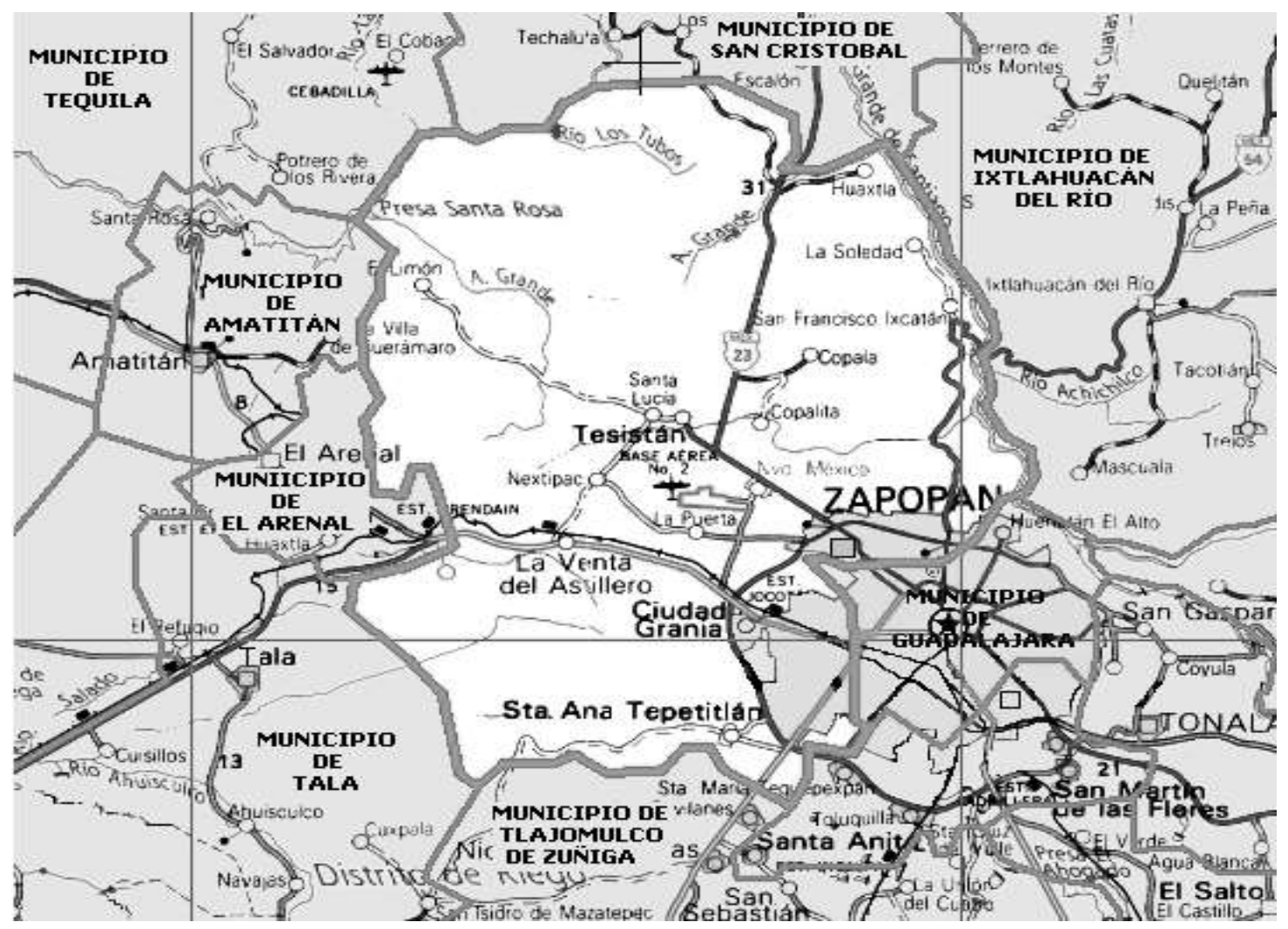

Fig. 1. Local and national connection of roads, airports, railways

The Agro ecological Park has a community garden where the citizens can grow and harvest organic food, a classroom built with natural materials, a module of dry ecological baths, a nursery area for plant production, a compost area for fertilizer processing and recycling nutrients, an edible forest, a rainwater harvesting, and distribution system and an ecological market area.

The surface is occupied by the project, which has 1.8 hectares, a neigh- borhood with about 40 thousand inhabitants, near the Pedagogical Water Forest in the area of the Colomos III Forest. Both parks are connected as part of a network of agro ecological parks in the Metropolitan Area of Guadalajara. What used to be rubble and rubbish dump is now the first Agro ecological Park in Zapopan, thanks to the work of the neighbors, the Teosintle Collective, and also with government support. It was inaugurated on March 27, 2015, by Mayor Hector Robles Peiro.

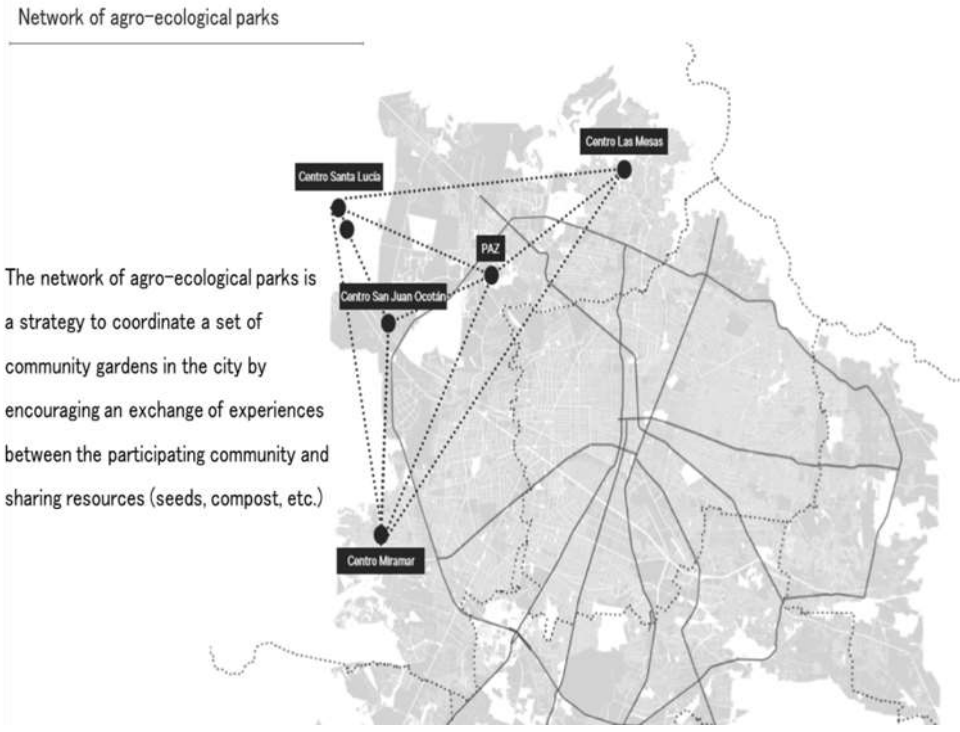

Fig. 2. The network of Agro ecological parks in the Guadalajara Metropolitan area. Source: Medina (2016). 
The "Pedagogical Forest of Water" has a local and national connection to roads, ports, railways, and walking accessibility to markets and customers.

\section{Environmental and Territorial Conditions}

The Municipal Urban Development Program of Zapopan aims to establish urban and environmental policies based on the determinations of the current programs and plans of the State Planning System, adequate and adjusted to the local needs and considering the established by the applicable environmental instruments in the municipal territory. The nature and characteristics of the Zapopan's ecosystem, within the environmental regionalization of the state is characterized by the environmental impact of new human settlements, agricultural, industrial, and commercial and service works or activities. The presence of more than half of the total population of the State in the Metropolitan Area of Guadalajara, being the municipalities of Guadalajara and Zapopan that shelter the greater part of this, generates a series of environmental and mobility problems.

Air pollution in Zapopan is one of the main pollutants generated in the metropolitan area. This is due to agricultural activities (burning), unpaved roads, diesel vehicles in circulation, combustion emissions in industry, forest fires, and suspension of dust from construction activities, including the transport of material and those extractive activities as is the case with material banks, among others.

The fraction particles smaller than 10 microns is the one that is most concentrated in the metropolitan area. The highest contribution in tons of pollutants corresponds to mobile sources, accounting for $96 \%$ of the emissions generated. Particles suspended in the atmosphere (PM10) are now considered to be the best indicator of air quality. They are constituted by nitrates and sulfates or by organic carbon - due to their conformation, which may be of natural origin or also by photochemical reaction (Rojas, 2012).

Another aspect that is involved in the problem of pollution in the MAG is the winds and their effects on the concentration and dispersion in the atmosphere of ozone and suspended particles; generally, at higher wind speeds, greater dilution of pollutants. The annual wind regime in the region is divided into two defined periods: One from November to June in which the West winds prevail, and from June to October in which the East winds prevail (Cohen, 1979).

Ozone, which is due to the reaction of hydrocarbons in the atmosphere, is another pollutant that has exceeded $100 \mu \mathrm{g} / \mathrm{m}^{3}$. As the easterly winds contribute to the ozone concentrations in the west of the MAG, mainly due to the frequency of calm periods, and the western winds carry the ozone towards the center. The slightly moderate winds of the southwest and southeast of The MAG transport this pollution to the north. For the spring period, there is a decrease in the air quality index since it registers 97 IMECA ozone points as the maximum level. Towards the north and south of Zapopan the season of the year that concentrates higher levels of pollution by particles of ozone in the winter.

In the case of Nitrogen dioxide $\left(\mathrm{NO}_{2}\right)$, whose main source is combustion in industries and vehicles (Mutebi, 2018), it turns out to be the other pollutant present in the atmosphere of the municipality of Zapopan. It is observed that $13.0 \%$ of $\mathrm{NO}_{2}$ measurements exceed $40 \mu \mathrm{g} / \mathrm{m} 3$, which is the annual average recommended by the World Health Organization (WHO). Sulfur dioxide $\left(\mathrm{SO}_{2}\right)$ - a product of the combustion of coal, diesel, fuel oil, and gasoline with sulfur, in addition to sulfur-rich metallic veins, industrial processes, and volcanic eruptions - has been located within limits established by both the Mexican standard of $340 \mu \mathrm{g} / \mathrm{m}^{3}$ and the WHO standard of $40 \mu \mathrm{g} / \mathrm{m}^{3}$.

This place was all constructed with natural materials. It counts with a main building, a classroom, an office, a small room that has domestic technologies, a dry bath module, and a community garden fenced with 47 beds of cultivation $\left(10 \mathrm{~m}^{2}\right.$ each) plotted by Raw Land but excavated in the rubble by Collective Teosintle Agro ecological and volunteers; Bamboo structure for composting and nursery of nurseries. It also has a winery built by Farid Morales in collaboration with DIF Zapopan, Collective Teosintle Agro ecological and other volunteers, while the bamboo structures were given and placed by Fernando Partida of BambuXal also with the help of the collective.

Due to the altitude and the hydrographic network of the region, it is considered that there are no sufficient water resources in quality and quantity to satisfy the current and future demand. The overexploitation of the aquifers and the presence of heavy metals such as arsenic, requires among other measures, improving the management of existing sources of freshwater and addressing the problems of waste and pollution control. Knowing this, it can be said that it is due to the change of land uses, with the urban spot's growth, both in residential areas and in areas of industrial use, where the pollutants have been present significantly affecting the environment.
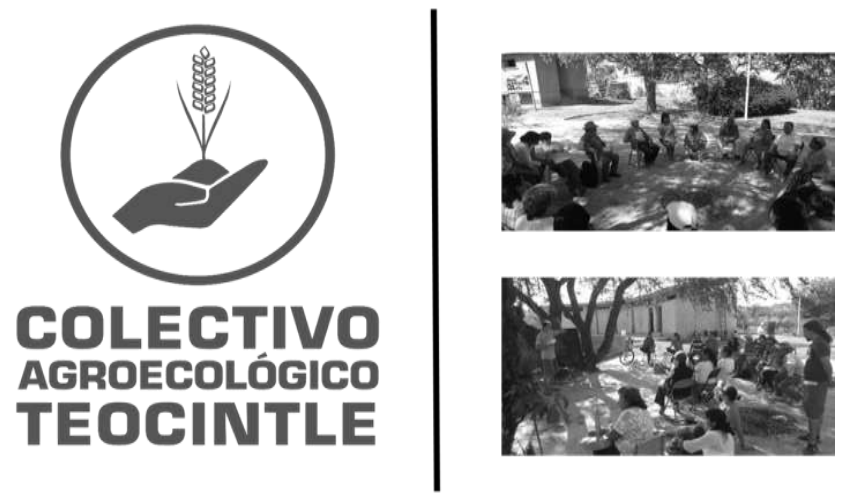

Fig. 3. Logo and Agro ecological park activities. Source: Medina (2016).

Zapopan Agro Ecological Park, a Space of Entrepreneurial Inclusion, Civil Culture and Technological Innovation

The Zapopan Agro ecological Park is in the bio-economy field of agro ecology food, health, and energy. It is an innovative public space that combines the direct participation of the community of an urban farm project that practices that support of the sustainability culture (such as the recollection of organic waste for the production of compost) as well as training workshops on different agro ecological themes to generate a unique space in the city open to all citizens. Within the programs of the Public Space Authority of the municipality, Zapopan focused on the needs of the community to generate job opportunities and entrepreneurship in the agro ecological Park.

The kids connect with the eco technicians, which can give them the opportunity to improve their own housing, generate construction projects, and self-construction (Martinez, 2016). The Zapopan Agro ecological Park, is a space open to all the public where, through workshops, practice and coexistence, there is collective learning on issues related to agro ecology, self-sufficiency, environmental knowledge and social awareness (Traffic MAG, 2016). This center of inclusion is a space that generates and promotes opportunities for local people (Martinez, 2016). 


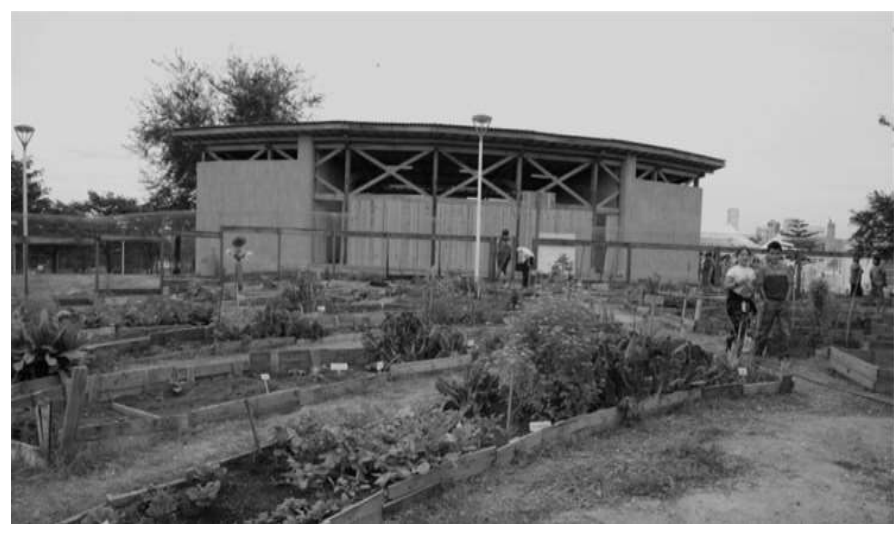

Fig. 4. The Orchards and the main building in the Agro ecological park. Source: Medina (2016).

Citizens are also able to have access to areas such as: An educational center built with natural materials, a boardroom/ library, a classroom, and an urban garden that is an important part of the project so the people can relate. The park has a nursery for the reproduction of plants, a compound area to produce fertilizers, a main square, the first West Edible Forest, ecological baths, a rainwater collection, and a distribution system to make the park self-sustainable. In addition, several ecological workshops, cultural and sports activities are being held within the areas (Zapopan Government, 2015).

In this space, it has been found that it had a fertile ground to grow: radish, chard, cabbage, lettuce, parsley, parsley, corn, beans, arugula, basil, chayote, broccoli, chili, potato, chives, sunflower, etc., are some of the more than eighty species of edible consumption, medicinal plants, etc. In the orchard, you can find crops of various vegetables such as chard, lettuce, lavender, squash, squash, arugula, onion, cilantro, parsley, pineapple, bean, celery, cabbage, chayote, tomato, green tomato, and African cucumber, among others (Rocha, 2016).

The main goal of this project is to continue fostering social cohesion and work for better health through orchards and urban agriculture. Zapopan Government has a agro ecological network of parks in strategic areas of the municipality. An agro ecological park is a perfect project for public space, an environmental sustainability component where people of the community can produce their own food.

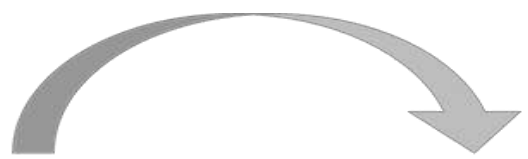

\section{Civic innovation sicicisiois}

Active participation

of the community in cooperative and self-management projects
Ecological innovation 6)

Community environmental projects:

- Eatable forest

- Organic waste management program for compost production

- Rainwater collection system

- Reforestation

- Integrated management of flora and fauna

- environmental education

Fig. 5. Civic innovation and ecological innovation cycle. Source: Medina (2016).

The Zapopan Agro ecological Park is a space that became a meeting and a development space for the community in an urban environment which is committed to sustainability and to organize events such as the "Teosintle" fest, which is celebrated to raise awareness about the existence of the capacity of the human beings to generate his own resources, this, to allow them to subsist (food, utensils) and to connect the community, land, work and practice their traditions. The events celebrated and organized in the park, offer different activities such as workshops of urban gardens, rally, craft market, food area, barter, dance, music, conversation and networking, outdoor cinema, among others (Traffic MAG, 2016). Cesar Medina in collaboration with the Municipal Government of Zapopan and the University Center of Biological and Agricultural Sciences (CUCBA) of Universidad de Guadalajara keeps working on this and other projects (Zapopan Gov- ernment, 2016).

As a matter of time spent starting with Raw Lands work, began with the drafting of the project to manage the funds in the month of June 2013. Many people have collaborated in the construction of this park, specifically Raw Land. The municipal government of Zapopan was in charge of the design and the general master plan of the park, construction of the classroomoffice complex, the module of dry baths and the perimeter fence of the orchard. The local authorities also were in charge of design and build the social aspect of the park, which means it generates the social-neighborhood appropriation for the project and trains them in agro ecological sowing. From this social process, the Collective Agro ecological Teosintle (CAT) has emerged (Zapopan Government, 2015). 


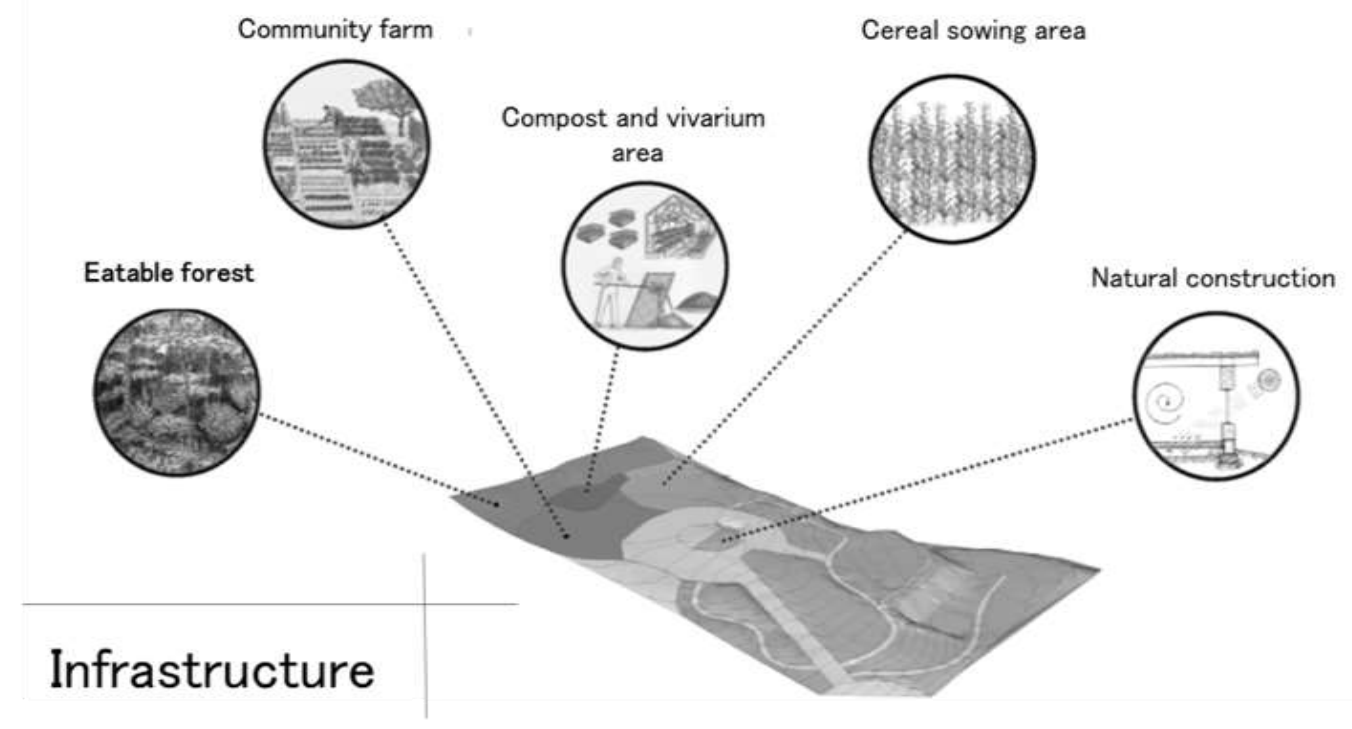

Fig. 6. Sketch and disposition of the Agro ecological park. Source: Zapopan Government (2015).

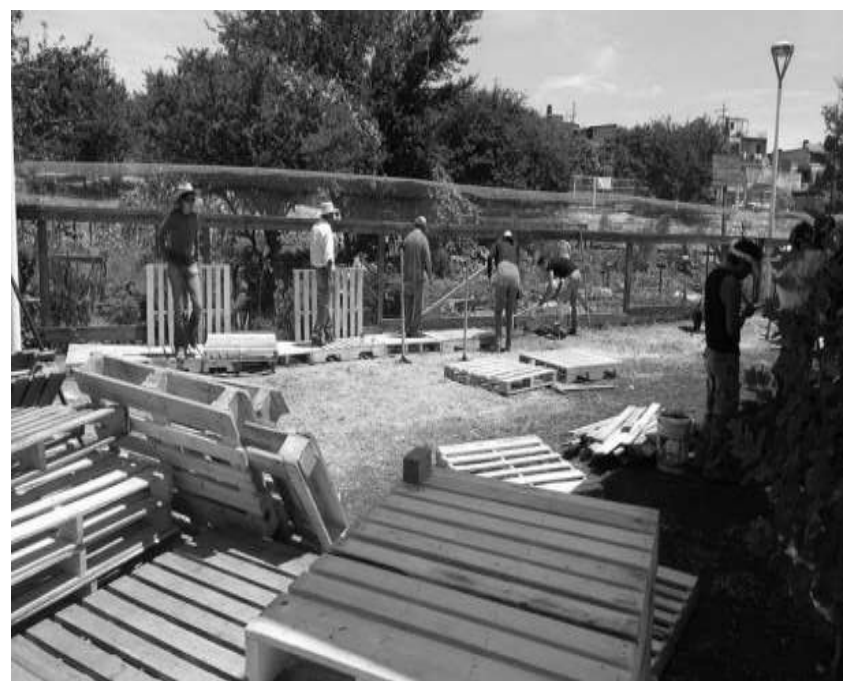

Fig. 7. PAZ construction process. Source: Traffic MAG (2016).

The people who work and participate in the park always produce their own compost, build beds, seek to improve and make innovations in environmental terms, seek the common good, and make decisions. The community garden is designed in a circular form for better use. Currently, there are 47 beds of cultivation available for anyone with knowledge in bio intensive crops and meets the requirements of the collective.

In the social matter, it can be said that the park was appropriated through its community gardening, where 32 families are working organized by the Collective Teosintle Agro ecological. In addition, this space offers several workshops to the neighbors of the park as the rest of the inhabitants of the Metropolitan Area of Guadalajara.

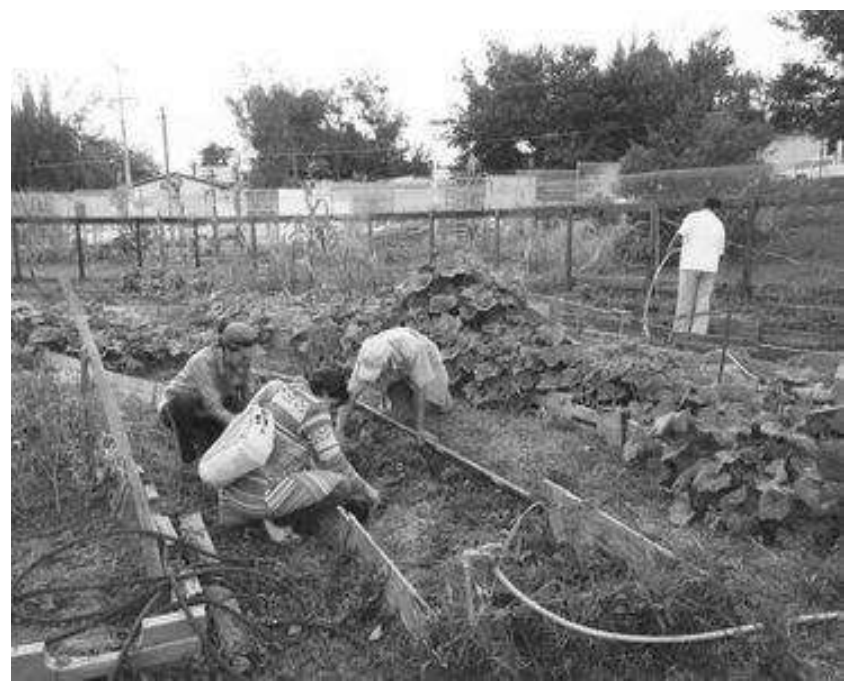

Fig. 8. People working in the orchards.

The municipality of Zapopan catapults this project with the collaboration of other civil organizations and universities in order to promote selfconsumption and environmental education. With the collaboration of the Collective Teosintle Agro ecological, Farid Morales, who became the coordinator of the park employed by DIF in Zapopan, officials of the institution, with the help of Carlos Bauche and Fernando Partida BambuXal, as well as the consultants for the general design of the park, the orchard and the edible forest by More Humus and also the Cooperative the Glens (Zapopan Government, 2015). The Teosintle Collective helps those who come and teach them how to grow their own food, making citizens feel productive and healthier.

Local Authorities from the municipality of Zapopan want to empower them, increase capacities with projects and workshops that are specialized in urban agriculture, and has knowledge in seed production and compost. All this focused on community organization. The municipality is in charge of coordinating and managing the workshops and activities of the collec- 
tive and community. Once a month, the local authority of the municipal government and the City Council organize a tour of different orchards, including this park that is open to the community and is a public space meaning that anyone can be part of it. Is important to say that the proper authority of this public space is responsible for the Park, which includes the orchard and the edible forest. It is managed by the collective Teosintle and is a project belonging to these local spaces authorities from the municipal administration of Zapopan, Jalisco. This is also impelled through the Direction of Public Spaces. Teosintle Agro ecological Collective is an organization that works in the management of the orchard of the park. The chief of the Public Spaces in Zapopan among Cesar Lepe Medina, coordinator of this project and manager of the Special projects of public spaces office in the city, is now in charge of this park.

The collective is divided into commissions involved in gardening activities. New people can decide if they want to be members. Currently, there are about 40 families from the community, represented by one person, that are part of the park.

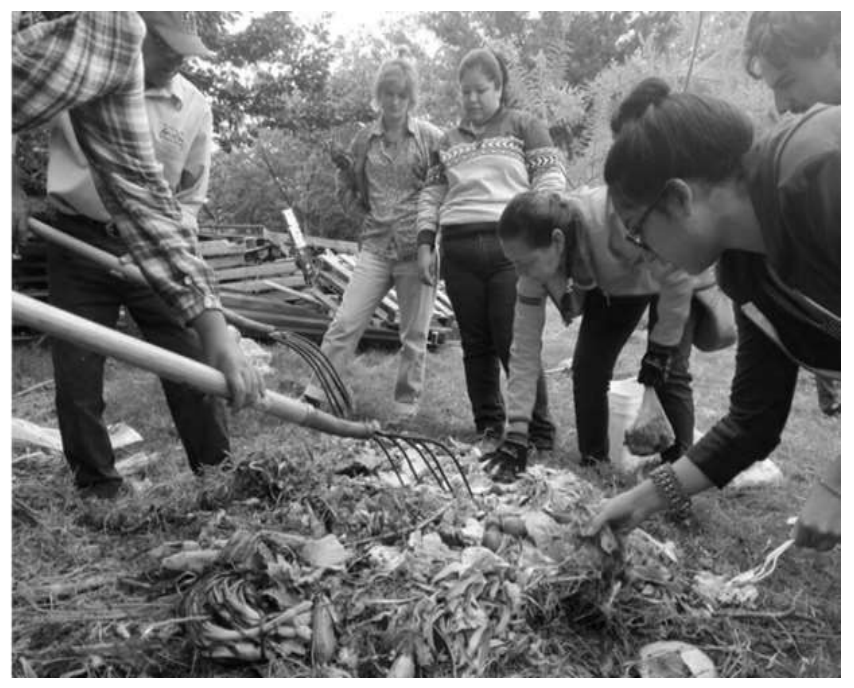

\section{Strategic management of Zapopan Agro ecological park}

Speaking of the financial part, the Zapopan Agro ecological Park had an investment of approximately 5 million pesos and has an important impact in 110 direct beneficiaries, in addition to the communities surrounding the park and people interested in participating in this project. The budget of the park has an income that comes from several sources of financing and contributions.

Zapopan Strategic Projects (PEZ)/Metropolitan Fund approximate figure, for a fund for the forest district of 10 million pesos out of which are allocated to Zapopan city of all $\$ 3,000,000.00$. The National Program for the Prevention of Crime (PRONAPRED) contributes to 1, 100, 000.00. DIF Zapopan- Donations Area with 950, 000.00 and Program Temporary Employment PET / SEMADET with 120, 000.00

Source: Own elaboration with data from Cesar Lepe Medina, coordinator of the project, and public servant of the Office of Special Projects of Public Space of the City.

The Agro ecological park is located on a farm with almost two hectares in the Metropolitan area of Guadalajara (MAG) that has the highest rate of violence and criminality. This space used to be a ravine, and that was filled with rubble. The first intervention took place with the construction of a board and with the installation of urban furniture and public lighting by the Special Projects of Zapopan Office (Zapopan Government, 2015).

This sustainable project also includes creating classrooms made from bamboo, a waste separation, and a recycling system of plastic, paper, glass, metal, organic waste, and PET. The park has a central classroom that was built with materials such as wood and straw. This building is contemplating its use to be a meeting point, a conference place, and a market display to give an opportunity to those who collaborate in the management of the ecological garden, giving them this space to offer their products. The park has a dry bath system that is used to reuse the generated waste as compost, and it also counts rainwater raining dam with a capacity of 750 -thousandliter rainwater harvesting board and 20-thousand-liter storage tank that will provide water to the orchard and forest during the dry season which was also constructed by Agro ecological Zapopan Park.

Fig. 9. Gardening activities of the actual members of the park. Source: Medina (2016).

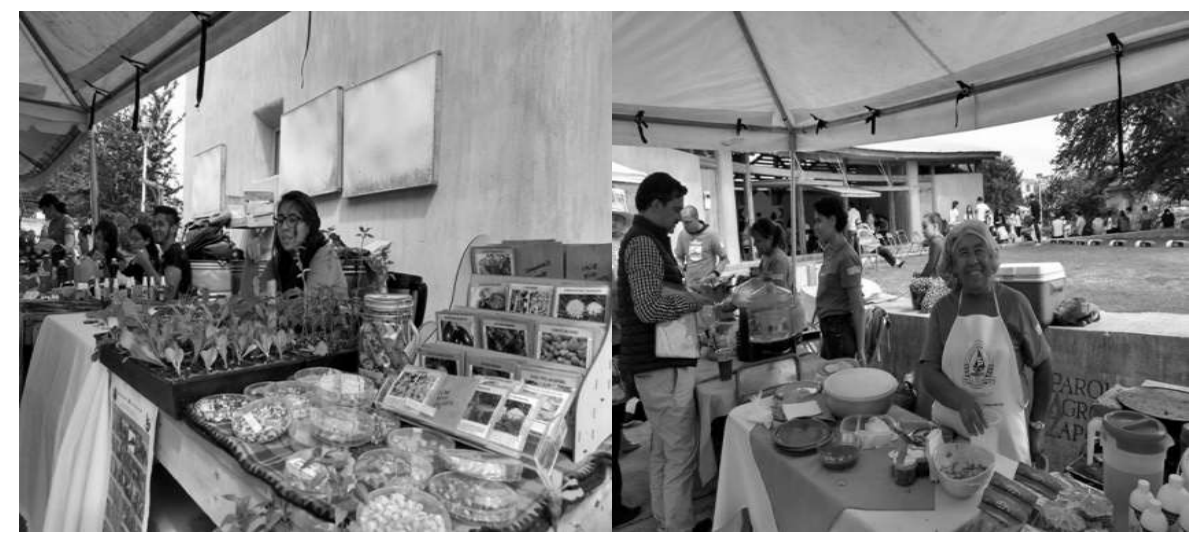

Fig. 10. Products from the orchards and events in the park, Source: Medina (2016).

As a result, the Local Authority of the Public Space of Zapopan, through the Zapopan Agro ecological Park, offers a space for community building and collaborative work, where one of its priorities is the orchard where 25 to 35 kilos of food are produced and harvested weekly. The production has several types of vegetables, fruits, medicinal plants, and ornament plants. There are more than 50 species as pumpkin, beet, sesame, strawberry, 
lettuce, Swiss chard, a bean that are gown in this park. Other products are elaborated with this harvests, such natural slurries or milk made from seeds such as almond or canary seed. The Solar dehydrators were created to dehydrate foods such as tomatoes, traditional footwear based on preHispanic roots, and even the elaboration of biocosmetics made with plants such as lavender and lemon.

The public perception is positive; nowadays, there are a lot of people who finds comfort and relief in this orchards, they like being part of something, connecting with people who feel the same way and are working hard to stay productive, to have a decent income and to live a better and healthier life. Environmental education also has a significant impact in the activities and people working in this park to make a sustainable lifestyle.

\section{Limitations and Future Research Directions}

This research has several limitations. Regarding access to information, the researchers could have data available from involved actors: The leaders and members of the Teosintle collective, officials from local government, users involved from the community, neighbors, etc. Therefore, the information and data came from first sources. There has not been any information and data available from academic papers and research reports, only very limited information given in local newspapers. Also, the municipal and local government has not any record at all, and the available information and data very limited.

Another limitation is related to the funds to support the research. A research project supported the original funding: "The Role of Green Innovation Areas in Revitalizing German and Mexican Cities", based on the applications of bio-economy, which was more aimed to conduct practices and analysis by exchange researchers and postgraduate students from the Technical University of Kaiserslautern University and from Universidad de Guadalajara. Financial support came from a binational source, the National Council for Science and Technology of Mexico, and the Bundesministerium Fur und Forschung. Also, the experience derived from the results has resulted in several conclusive elements that can be the base for recommendations. This is a highly interesting and innovative project with social, economic, environmental, and governance impacts for all the stakeholders involved. The analysis and study of this case, Zapopan Agro ecological Park as an urban green innovation area, has the potential to connect the sphere of bio-economy with the requirements of urban development and land uses. For these reasons, it is highly recommended to replicate these experiences and practice, as it has already been the case here in the Metropolitan Area of Guadalajara and Kaiserslautern, Germany.

\section{Conclusion}

Zapopan Agro ecological Park is a model of entrepreneurial, inclusive civil culture. This park marks a milestone in the regeneration of public spaces with a project of social and environmental relevance. It is important to mention that the park was a wasteland and a place of total disuse.
A total of 1.8 hectares, on Santa Laura Street, in the colony Santa Margarita (colony with more than 33 thousand inhabitants), now live in peace. This place has now recovered from being abandoned, and today is the reflection of hard work and creativity of citizens and authorities that are a model for this public space with pedagogical purposes and for the constant neighborhood participation.

\section{References}

Cohen, M. (1979). Air pollution and health. Guadalajara, Mexico: IGE.

IIEG. (2015). Technical note jalisco registers 7.8 million residents at the beginning of 2015 (Tech. Rep.). National Institute of Statistical and Geographical Information, Aguascalientes City, Aguascalientes.

IIEG. (2016). Municipal diagnosis september-16 (Tech. Rep.). National Institute of Statistical and Geographical Information, Aguascalientes City, Aguascalientes.

INEGI. (2011). General census of population and housing 2010. Retrieved from https://bit.1y/36pQheE

Martinez, I. (2016). Zapopan seeks to be a child friendly city. Retrieved from https://bit.1y/2UndY1C

Medina, C. (2016). The role of innovation in green areas for the revitalization of German and Mexican cities. In Green Innocvation Areas, Guadalajara, Mexico.

Mutebi, D. (2018). Reducing global warming and stopping unnecessary pollution through regulating and levying private transport means in Bandung. International Journal of Humanities, Arts and Social Sciences, 4(6), 253-261. doi:https://doi.org/110.20469/ijhss.4.10004-6

Rocha, A. (2016). The mirror: Zapopan Agro ecological park, cultivation area in the metropolis. Retrieved from https://bit.1y/2H1auPm

Rojas, H. (2012). A decade of participation of the Vallarta Ports gross domestic product to the state of Jalisco, 2000-2009. Research and Science of the Autonomous University of Aguascalientes, 54, 30-39.

Traffic MAG. (2016). Zapopan agro ecological park celebrates selfsustainability. Retrieved from https://bit.ly/3eVMR72

Zapopan Government. (2015). Zapopan launches agro ecological park. Retrieved from https://bit.1y/2IwTIrK

Zapopan Government. (2016). Zapopan agro ecological park: A model of sustainable urban agriculture. Retrieved from https://bit.ly/ 32DU9HQ 